University of Nebraska - Lincoln

DigitalCommons@University of Nebraska - Lincoln

Publications, Agencies and Staff of the U.S.

Department of Commerce

U.S. Department of Commerce

$1-2003$

\title{
The Abundance of Harbor Seals in the Gulf of Alaska
}

Peter Boveng

National Marine Mammal Laboratory, Alaska Fisheries Science Center, National Marine Fisheries Service, NOAA, peter.boveng@noaa.gov

John Bengtson

National Marine Mammal Laboratory, Alaska Fisheries Science Center, National Marine Fisheries Service, NOAA

David Withrow

National Marine Mammal Laboratory, Alaska Fisheries Science Center, National Marine Fisheries Service, NOAA

Jack Cesarone

National Marine Mammal Laboratory, Alaska Fisheries Science Center, National Marine Fisheries Service, NOAA

Michael Simpkins

National Marine Mammal Laboratory, Alaska Fisheries Science Center, National Marine Fisheries Service, NOAA

See next page for additional authors

Follow this and additional works at: https://digitalcommons.unl.edu/usdeptcommercepub

Part of the Environmental Sciences Commons

Boveng, Peter; Bengtson, John; Withrow, David; Cesarone, Jack; Simpkins, Michael; Frost, Kathryn; and Burns, John, "The Abundance of Harbor Seals in the Gulf of Alaska" (2003). Publications, Agencies and Staff of the U.S. Department of Commerce. 146.

https://digitalcommons.unl.edu/usdeptcommercepub/146

This Article is brought to you for free and open access by the U.S. Department of Commerce at DigitalCommons@University of Nebraska - Lincoln. It has been accepted for inclusion in Publications, Agencies and Staff of the U.S. Department of Commerce by an authorized administrator of DigitalCommons@University of Nebraska - Lincoln. 


\section{Authors}

Peter Boveng, John Bengtson, David Withrow, Jack Cesarone, Michael Simpkins, Kathryn Frost, and John Burns 


\title{
THE ABUNDANCE OF HARBOR SEALS IN THE GULF OF ALASKA
}

\author{
PETER L. BOVENG \\ JOHN L. BENGTSON \\ DAVID E. WITHROW \\ Jack C. Cesarone \\ Michael. A. SimpKins \\ National Marine Mammal Laboratory, \\ Alaska Fisheries Science Center, \\ National Marine Fisheries Service, NOAA, \\ 7600 Sand Point Way NE, \\ Seattle, Washington 98115 , U.S.A. \\ E-mail: peter.boveng@noaa.gov \\ KATHRYN J. FroST \\ University of Alaska Fairbanks, \\ School of Fisheries and Ocean Sciences, \\ 1550 Coyote Trail, Fairbanks, \\ Alaska 99709, U.S.A. \\ JOHN J. BURNS \\ Living Resources, Inc., \\ P. O. Box 83570 , \\ Fairbanks, Alaska 99708, U.S.A.
}

\begin{abstract}
The abundance of harbor seals (Phoca vitulina richardii) has declined in recent decades at several Alaska locations. The causes of these declines are unknown, but there is concern about the status of the populations, especially in the Gulf of Alaska. To assess the status of harbor seals in the Gulf of Alaska, we conducted aerial surveys of seals on their haul-out sites in August-September 1996. Many factors influence the propensity of seals to haul out, including tides, weather, time of day, and time of year. Because these "covariates" cannor simultaneously be controlled through survey design, we used a regression model to adjust the counts to an estimate of the number of seals that would have been ashore during a hypothetical survey conducted under ideal conditions for hauling out. The regression, a generalized additive model, not only provided an adjustment for the covariates, but also confirmed the nature and shape of the covariate effects on haul-out behavior. The number of seals hauled out was greatest at the beginning of the surveys (mid-August). There was a broad daily peak from about 1100-1400 local solar time. The greatest numbers were hauled out at low tide on terrestrial sites. Tidal state made little difference in the numbers hauled out on glacial ice, where the area available to seals did not fluctuate
\end{abstract}


with the tide. Adjusting the survey counts to the ideal state for each covariate produced an estimate of 30,035 seals, about 1.8 times the total of the unadjusted counts $(16,355$ seals). To the adjusted count, we applied a correction factor of 1.198 from a separate study of two haul-out sites elsewhere in Alaska, to produce a total abundance estimate of 35,981 (SE 1,833). This estimate accounts both for the effect of covariates on survey counts and for the proportion of seals that remained in the water even under ideal conditions for hauling out.

Key words: harbor seal, Phoca vitulina, aerial survey, abundance, Gulf of Alaska, generalized additive model, negative-binomial regression.

In Alaska, harbor seals (Phoca vitulina richardii) occupy a broad range from approximately $130^{\circ} \mathrm{W}$ to $172^{\circ} \mathrm{E}$ (over $3,500 \mathrm{~km}$ east to west) and from $61^{\circ} \mathrm{N}$ to $51^{\circ} \mathrm{N}$ (over $1,000 \mathrm{~km}$ north to south) (Frost et al. 1982). In recent decades their abundance has declined at several Alaska locations. For example, counts of harbor seals at Tugidak Island declined 85\% between 1976 and 1988 (Pitcher 1990) and counts in Prince William Sound suggest population declines of approximately $63 \%$ between 1984 and 1997 (Frost et al. 1999). The significance and causes of these declines are unknown, but there is concern about the present and future status of Alaska harbor seal populations, most notably in the Gulf of Alaska. Declining populations of Steller sea lions (Eumetopias jubatus), which are sympatric with harbor seals through most of their range, have added to concerns about what may be happening to harbor seal populations; the western stock of Steller sea lions has declined by over 70\% since the mid-1960s (Loughlin et al. 1992) and was listed in 1997 as "endangered" under the U.S. Endangered Species Act.

Reliable estimates of harbor seal abundance are needed to develop sound conservation and management plans. The most feasible approach to estimating regional abundance is to use aircraft to count seals when they are hauled out of the water and are visible. Understanding the timing of haul-out behavior, therefore, is of critical importance to survey design. Harbor seals generally haul out in greatest numbers during mid-day (e.g., Schneider and Payne 1983, Stewart 1984, Yochem et al. 1987, Watts 1996), though this may vary by region (e.g., Frost et al. 2001), or even by haul-out site (Ver Hoef and Frost, in press). Also, there are two seasonal peaks in the numbers of harbor seals hauled out in Alaska: one during May/June associated with pupping, and the other during August/September associated with molting (Jemison and Kelly 2001). In Alaska, aerial surveys have generally been conducted during the molting period when the number of seals hauled out was thought to be highest and the weather conditions were likely to be favorable for flying.

In addition to time of day and date, environmental conditions such as tide level and local weather affect the haul-out behavior of harbor seals. These and other covariates of seal counts should be factored into analyses to account for seals that were not hauled out when the counts were made. Watts (1996), Frost et al. (1999), and Ver Hoef and Frost (in press) used this approach to analyze trends of harbor seal counts in British Columbia, Canada, and Prince William Sound, Alaska. In the present paper we used the same general analytical approach of incorporating survey covariates, but our focus was on the abundance of seals in a broad area, the Gulf of Alaska, rather than on trends in seal counts at a relatively small number of haul-out sites. The aims of this study were (1) to gain a better understanding of how environmental conditions affect the timing and 
numbers of seals hauled out during aerial surveys, (2) to reduce the effects of variability from covariates on estimates of harbor seal abundance, and (3) to estimate the total number of harbor seals in the Gulf of Alaska.

\section{METHODS}

\section{Study Area}

The study area was composed of seven survey zones distributed along the Gulf of Alaska coastline (Fig. 1): (1) the south side of the western Alaska Peninsula from Cape Lazaref to Kupreanof Peninsula (including the Shumagin Islands); (2) the south side of the eastern Alaska Peninsula from Chignik Bay to Cape Douglas Reef (including Semidi and Chirikof islands); (3) the Kodiak Archipelago (including Afognak, Tugidak, and Sitkinak islands); (4) the north side of Cook Inlet from Anchorage to Cape Douglas; (5) the Kenai Peninsula; (6) Prince William Sound; and (7) the Copper River Delta, Middleton Island, and Kayak Island.

Harbor seals were counted at 299 haul-out sites distributed throughout the seven survey zones (Fig. 1, Table 1). This distribution of survey effort covered nearly all the haul-out sites (e.g., beaches, ledges, sand bars, offshore rocks, and glacial ice) used by harbor seals in the Gulf of Alaska, except in Prince William Sound. There, "rrend routes" were monitored in studies sponsored by the Alaska Department of Fish and Game (Route A; Frost et al. 1999) and the Exxon Company, U.S.A., (Route B; Hoover-Miller et al. 2001). The trend routes were designed to monitor seal population trends over several years at selected, well-known haul-out sites rather than monitor total abundance at all haul-out sites. The two trend routes encompassed the majority of haul-out sites in Prince William Sound, but (because some glacial areas were excluded along Route B) the number of haul-out sites that were not surveyed is unknown. In 1996 there were six sites along Route $A$ where no seals were encountered, and two sites where only one seal was encountered on one day of the surveys; these eight sites were not included among the 299 sites that we analyzed. Other than the difference in how sites were selected for trend routes $v s$. other areas, the survey methods were the same for all areas surveyed.

\section{Survey Methods}

Fixed-wing aircraft were used to photograph harbor seals hauled out on land or ice from 12 August through 6 September 1996. Those dates fell within the period identified previously as the annual molting period, when the greatest number of harbor seals spend the greatest amount of time hauled out (Pitcher and Calkins 1979, Calambokidis et al. 1987). Observers in nine separate aircraft were used to survey the seal haul-out sites during the study period (Table 1). Survey flights were scheduled to occur within two hours on either side of low tide, as permitted by available daylight and weather. Most surveys were flown at an altitude between $100 \mathrm{~m}$ and $300 \mathrm{~m}$ at about $167 \mathrm{~km} / \mathrm{h}$ ( $90 \mathrm{knots})$.

At the beginning of the survey period, the entire coastline in each survey zone (except Prince William Sound) was searched to determine the location of all harbor seal haul-out sites. Haul-out sites found during that comprehensive search were surveyed on (up to 12) subsequent days. Ninety percent of sites were counted two or more times, and $66 \%$ of sites were counted four or more times. 

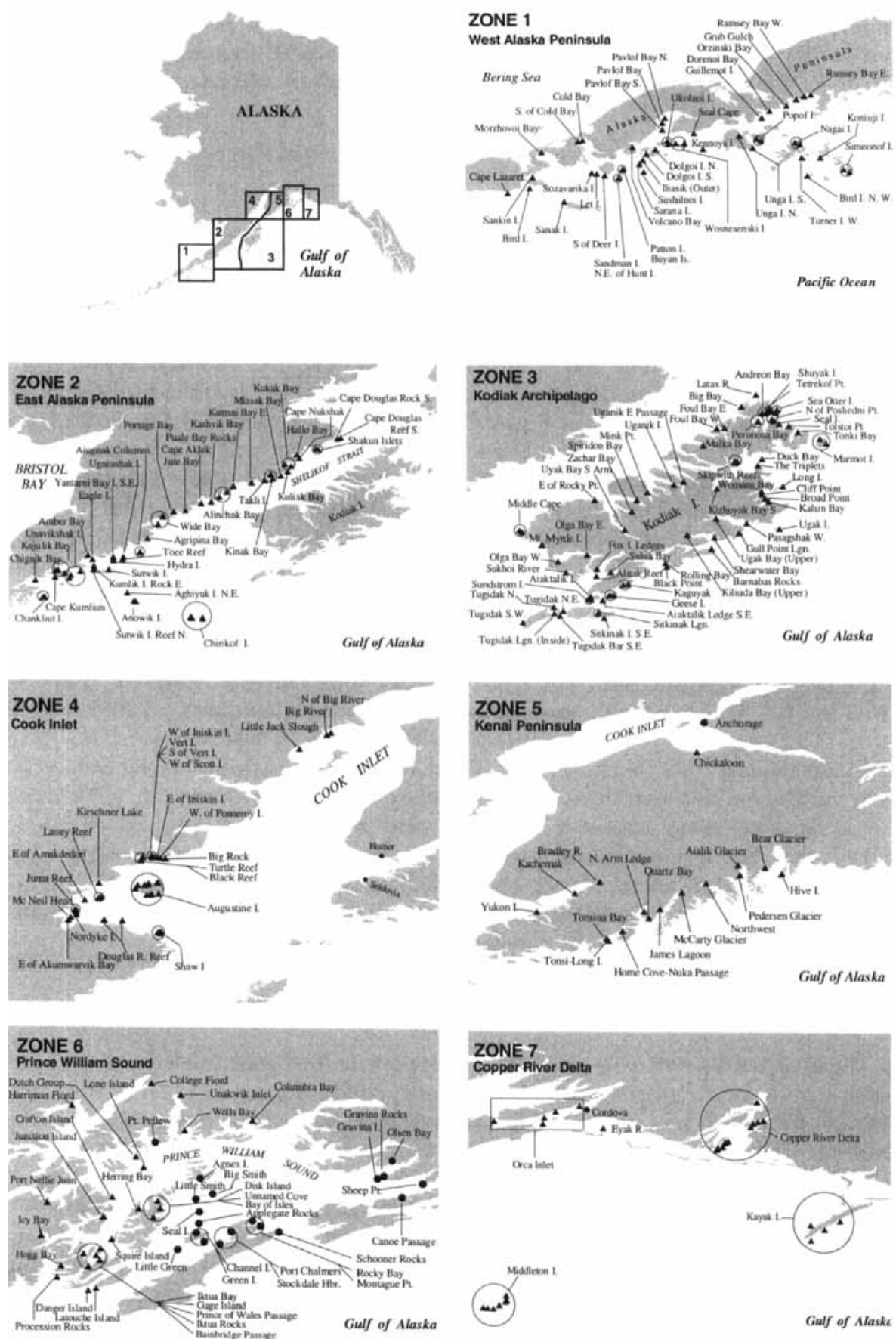

Figure 1. Location of seven survey zones in which harbor seals were counted during 1996 aerial surveys. In Zone 6, Prince William Sound, sites on Route A designated by solid circles and sites on Route B by triangles. 
Table 1. Survey dates, locations, number of haul-out sites, and aircraft used in the 1996 Gulf of Alaska harbor seal surveys.

\begin{tabular}{clcll}
\hline \hline $\begin{array}{c}\text { Survey } \\
\text { area }\end{array}$ & \multicolumn{1}{c}{$\begin{array}{c}\text { Number of } \\
\text { haul-out sites }\end{array}$} & \multicolumn{1}{c}{ Dates } & \multicolumn{1}{c}{ Aircraft } \\
\hline 1 & West Alaska Peninsula & 46 & 25 Aug-1 Sep & Aero Commander \\
2 & East Alaska Peninsula & 55 & 25-30 Aug & Aero Commander \\
3 & Kodiak Archipelago & 79 & 25 Aug-3 Sep & (2) Cessna 206 \\
4 & Cook Inlet & 44 & 25 Aug-2 Sep & Cessna 206 \\
5 & Kenai Peninsula & 14 & 26 Aug-2 Sep & Cessna 185 \\
6 & Prince William Sound & & & \\
& $\quad$ Route A & 17 & $12-26$ Aug & Cessna 185 \\
& $\quad$ Route B & 25 & 12 Aug-6 Sep & Cessna 206 \\
7 & Copper River Delta & 19 & 27 Aug-3 Sep & Cessna 185 \\
\hline
\end{tabular}

Groups of $<10$ seals (or $<40$ for Prince William Sound surveys) were counted with the naked eye or with $7 \times$ binoculars as the plane passed by or circled over the haul-out site. Larger groups were photographed with $35-\mathrm{mm}$ cameras and $70-210-\mathrm{mm}$ or $35-135-\mathrm{mm}$ zoom lenses using ASA 400 color transparency film. The color transparencies were projected onto a white background and the seals were counted, usually by two counters working independently (in which case, the mean of the two counts was used).

\section{Estimating Tide Heights and Times}

For each survey count at each haul-out site, we estimated the height of the tide, as well as the height and time of the low tide nearest to the time of each count. We used the predicted values of these variables from the closest station in the National Water Level Observation Network (Hicks 1989), established and monitored by the National Oceanic and Atmospheric Administration (http:// www.co-ops.nos.noaa.gov/). We used the tidal data from the station that was nearest by sea to each harbor seal haul-out site. The median distance by sea between each haul-out site and the nearest tidal station, weighted by the number of counts at each site, was $15 \mathrm{~km} ; 90 \%$ of the distances were $\leqslant 41 \mathrm{~km}$. The heights and times of the tides were estimated using the program WXTIDE32 (http://www.wxtide32.com/). ${ }^{1}$

\section{Deriving Maximum and Mean Harbor Seal Counts}

The number of seals counted during aerial surveys represents an estimate for the lower bound of the population size. However, when seals are counted on multiple days and no single day of the survey includes counts at all of the haulout sites, there are several methods of summarizing the number of seals counted. One option is to use the maximum number of harbor seals counted at each site throughout the survey period. In our case these site-specific maxima did not gen-

\footnotetext{
${ }^{1}$ Reference to products or trade names does not imply endorsement by the National Marine Fisheries Service.
} 
erally occur on the same day, raising the possibility that some seals may have been included in the maximum count more than once if they moved from one haul-out site to another. Although tagging studies indicate that harbor seals usually have small ranges (e.g., Pitcher and McAllister 1981, Stewart et al. 1989, Thompson et al. 1994, Lowry et al. 2001), the frequency with which groups of seals move between nearby haul-out sites is unknown. Therefore, for comparison, and to provide an estimate that would be less affected by movements of seals among sites, the mean number of seals counted at each haul-out site (sum of counts divided by number of replicate counts) was summed over all haul-out sites.

\section{Statistical Analysis of Factors Affecting Seal Haul-out Bebavior}

We modeled the effects of environmental variables (covariates) on the numbers of harbor seals hauled out during surveys using a method similar to that used by Frost et al. (1999), except that instead of a generalized linear model (McCullagh and Nelder 1989), we used a generalized additive model (Hastie and Tibshirani 1990, Fewster et al. 2000). Generalized additive models (GAMs) are non-parametric or semiparametric extensions of generalized linear models, allowing the data themselves to suggest the form of the relationships between harbor seal counts and the covariates, rather than requiring the analyst to specify a parametric form. In a second departure from the methods of Frost et al. (1999), we assumed that the number of harbor seals $Z_{i j}$ counted on the $j$ th flight over haulout site $i$ was distributed as a negative binomial random variable (rather than Poisson) with mean $\lambda_{i j}$ determined by a natural-log link function,

$$
\operatorname{Pr}\left(Z_{i j}=z\right)=\frac{\Gamma(\theta+z)}{\Gamma(\theta) z !} \frac{\lambda_{i j}^{z} \theta^{\theta}}{\left(\lambda_{i j}+\theta\right)^{\theta+z}}, \quad \ln \left(\lambda_{i j}\right)=\sum_{k} f_{k}\left(X_{i j k}\right),
$$

where $f_{k}$ is some function of $X_{i j k}$, the state of the $k$ th covariate (or set of covariates), and $\theta$ is a scale parameter for the relationship between the negative binomial mean and variance. The negative binomial distribution is often used for data, such as ours, that are "overdispersed" relative to the Poisson distribution (Lawless 1987). The functions $f$, called the additive predictors, may be chosen from a broad class of functions including non-parametric smoothers, which are especially useful in exploring or confirming the forms of the dependence of the counts on the covariates. We estimated the additive predictors and model parameters using the statistical software S-Plus $2000^{(\circledR)}$.

The covariates that we investigated were the height of the tide at the time of the count, height of the low tide nearest in time to the count, height and time of the tide relative to the nearest low tide (which we called relative tide height and relative tide time), time of day, date, wind speed, sky condition, and air temperature. The effects of tide, time, and date were modeled as smooth nonparametric functions and the other effects were modeled as categorical factors. One additional factor with two levels indicating whether the haul-out site was on land or floating ice was not included directly in the models but was used to "nest" the tidal covariates. In other words, the effect of a tidal variable such as relative tide height was modeled as two separate smooth functions: one for haulout sites on land and one for haul-out sites on ice. Finally, haul-out site identity was included as a categorical factor, providing a term for the site means. 
To select the covariates and the forms of the additive predictors that provided the best (i.e., most parsimonious) fit to the harbor seal counts, we used a stepwise procedure. We began with the model that contained all the covariates. We then dropped covariate terms one at a time, except for the term for site means, which was retained in all models. At each step, the single term that was least significant (assuming that the increment in the deviance was distributed as chisquared) was dropped until removing any further terms would cause a significant $(P<0.05)$ increase in the residual deviance. We also fit a model containing only the term for the site means. This model provided the means of the raw counts at all haul-out sites and served as a basis for comparison with the final counts adjusted for the effects of the covariates.

Our choice of the negative binomial distribution for the counts complicated the process of selecting a model from the covariates because the analysis of deviance (McCullagh and Nelder 1989) required that $\theta$ be known and fixed. We fixed $\theta$ at a value that we estimated in two ways. First, we fit a "full" GAM based on a Poisson distribution and containing all the covariates. We added the residuals from this model to the respective site means, simulating a new response variable with dispersion that was as independent as possible of the covariates. Eight values of this new response out of 1,366 were negative and were omitted from the next step. We then used the functions glm.nb and neg.bin from the MASS library for S-Plus (Venables and Ripley 1999) in a model with a term for sites as the only covariate to obtain an estimate of $\theta=4.17$. In a second approach, after examining the additive predictors from the "full" model described above, we replaced the non-parametric additive predictors with suitable, low-order polynomials and used glm.nb to obtain an estimate of $\theta=3.15$. We held $\theta$ fixed at 3.66 , the mean of the two estimates, during the stepwise model selection procedure described above.

The smooth terms were initially fit with a default degree of smoothing that provided approximately 4 degrees of freedom (1 degree of freedom corresponds to a linear fit, 4 degrees of freedom will typically accommodate moderate curvature and inflections). After selecting the covariates to include in the model, we checked our choices of the degree of smoothing to use in the predictors for tide, time, and date by allowing each term to be a linear term (slope), or a smooth term with either 4 or 7 approximate degrees of freedom (the latter can accommodate sufficient curvature to fit any reasonable form for the covariate effects we studied). These alternatives were evaluated by analysis of deviance using the approximate chi-squared test as in the selection of covariates. Like Frost et al. (1999), we checked the final model by examining the deviance residuals for patterns related to the covariates.

\section{Adjusting for Covariates}

To assess the combined effects of the covariates on the number of seals hauled out, we used the estimated covariate relationships to adjust the counts to a standardized set of conditions. These conditions were chosen as the value of each covariate that would be expected to maximize the number of seals ashore. This standardized set of conditions represented a hypothetical state that was unlikely to occur naturally. Nevertheless, it was instructive for assessing the overall impact of the covariates and for comparisons with other types of information (for instance, radio-telemetry based mark-resight studies) about the proportion of seals missed in aerial surveys. 
Correcting for the Proportion of Seals Not Hauled Out

There is no way to estimate, from counts alone, how many seals remain in the water even under ideal conditions for hauling out. This problem, common to all surveys of harbor seal abundance, has typically been addressed by using radiotelemetry or time-depth recorders to estimate the average proportion of seals hauled out during a survey and by using the reciprocal of that proportion as a "correction factor" applied to the unadjusted mean counts (e.g., Pitcher and McAllister 1981, Harvey 1987, Yochem et al. 1987, Hanan 1996, Olesiuk 1999, Huber et al. 2001). To create a correction factor for our covariate-adjusted counts, however, the telemetry data must themselves be adjusted for the state of the covariates. A correction factor that encompassed a range of haul-out conditions would over-correct if applied to a count that had been adjusted to ideal conditions. We had, unfortunately, no telemetry data directly associated with our harbor seal surveys of the Gulf of Alaska in 1996. However, Simpkins $e t$ al. ${ }^{2}$ indicated that it may be possible to use covariate-adjusted correction factors obtained elsewhere to estimate total harbor seal abundance in the Gulf of Alaska. We applied a covariate-adjusted correction factor from that study of 1.198 (SE 0.039) to obtain an estimate of the total number of harbor seals in the Gulf of Alaska. We estimated the variance of the total population estimate $N$, assuming independence of variables (Goodman 1960):

$$
\operatorname{var}(N)=\operatorname{var}(A C) \cdot C F^{2}+A C^{2} \cdot \operatorname{var}(C F)-\operatorname{var}(A C) \cdot \operatorname{var}(C F),
$$

where $A C$ is our adjusted count, and $C F$ is the correction factor.

\section{RESULTS}

\section{Seal Counts}

A total of 1,366 counts of harbor seals and the associated covariates were recorded. The maximum and mean numbers of seals counted within each survey zone are presented in Table 2. The sum of the unadjusted (i.e., raw data) means of the counts from all 299 haul-out sites was 16,355 seals; the sum of the unadjusted maximum counts was 23,815 seals.

\section{Model Selection}

The final model included terms for date, time of day, relative tide height (separate curves for land and ice sites), wind speed, and sky condition. Absolute tide height was dropped from consideration in the models because it was highly correlated with relative tide height, and the latter consistently improved the fit by a much greater margin. Of the remaining covariates, the first to be eliminated in the stepwise procedure was the height of the low tide nearest in time to the seal count. Two more covariates, air temperature and relative tide time, were eliminated before all the remaining terms in the model were significant $(P<0.05)$.

\footnotetext{
${ }^{2}$ Simpkins, M. A., D. E. Withrow, J. C. Cesarone and P. L. Boveng. Stability in the proportion of harbor seals hauled out under locally ideal conditions. National Marine Mammal Laboratory, 7600 Sand Point Way NE, Seattle, WA 98115, U.S.A.
} 
Table 2. Summary statistics of counts, adjusted counts, and population estimates of harbor seals in Gulf of Alaska during 1996.

\begin{tabular}{|c|c|c|c|c|c|c|c|}
\hline \multirow{2}{*}{$\begin{array}{l}\text { Survey } \\
\text { area }\end{array}$} & \multirow[b]{2}{*}{ Location } & \multicolumn{2}{|c|}{ Unadjusted counts } & \multicolumn{2}{|c|}{ Adjusted counts } & \multicolumn{2}{|c|}{ Population size } \\
\hline & & Maximum & Mean & Estimate & SE & Estimate & SE \\
\hline 1 & West Alasl & & 1,324 & & 212 & 3,136 & 274 \\
\hline 2 & & & & & & & 333 \\
\hline 3 & $\mathrm{Kod}$ & & & & 4 & & 653 \\
\hline 4 & Cook Inlet & & 2,237 & & 3 & & 456 \\
\hline 5 & Kenai Peninsula & 4 & 559 & 59 & 135 & ,269 & 167 \\
\hline \multirow[t]{3}{*}{6} & Prince & & & & & & \\
\hline & & & 7 & 9 & 69 & & 91 \\
\hline & Route B & 3,262 & 2,234 & 3,557 & 474 & & 584 \\
\hline 7 & Copper River Delta & 4,067 & 3,053 & 5,760 & 822 & 6,900 & 1,010 \\
\hline Total & Gulf of Alaska & 23,815 & 16,355 & 30,035 & 1,177 & 35,981 & 1,833 \\
\hline
\end{tabular}

The data did not support allowing any of the smooth terms to have 7 degrees of freedom. The default target of $\mathbf{4}$ degrees of freedom was supported for time of day and relative tide height at land sites. For date and relative tide height at ice sites, the smooth terms with 4 degrees of freedom did not provide a significantly better fit than the linear form for those terms. However, the difference in predicted values between the model with 4 degrees of freedom for those terms and the model with 1 degree of freedom for those terms was nearly imperceptible. We retained the smooth terms with 4 degrees of freedom as the best indicators of the general relationships between these variables and the numbers of seals hauled out, because the smooth term for date seemed to provide some information about the position of a peak in the effect of date on counts.

\section{Effects of the Covariates}

At haul-out sites on land, greater relative tide height had a depressive effect on the number of seals counted (Fig. 2). A hump in the curve at about $2 \mathrm{~m}$ of relative tide height was influenced by haul-out sites in southern Cook Inlet, suggesting that our tide prediction may have been inaccurate for those sites or perhaps that some of those sites actually afford better haul-out conditions when the ride is not too low. This situation has been observed where mud flats exposed at low tide isolate the seals from higher, more preferred grassy patches in Hood Canal, Washington. ${ }^{3}$ The effect on counts taken at relative tide heights greater than about $2 \mathrm{~m}$ was imprecise because there were few observations under those conditions. On ice haul-out sites, where the area available for hauling was not affected by tides, the effect of tide was both imprecise and without a clear pattern (Fig. 2), indicating that tide was not an important covariate of numbers of seals counted on ice.

Seal counts declined with date from the beginning of the study on 12 August until the end on 6 September (Fig. 2). Although the curve describing the effect

\footnotetext{
${ }^{3}$ Personal communication from Glenn R. VanBlaricom, U.S. Geological Survey, Biological Resources Division, Washington Cooperative Fish and Wildlife Research Unit, School of Fisheries, University of Washington, Seattle, Washington 98105, U.S.A., September 2001.
} 

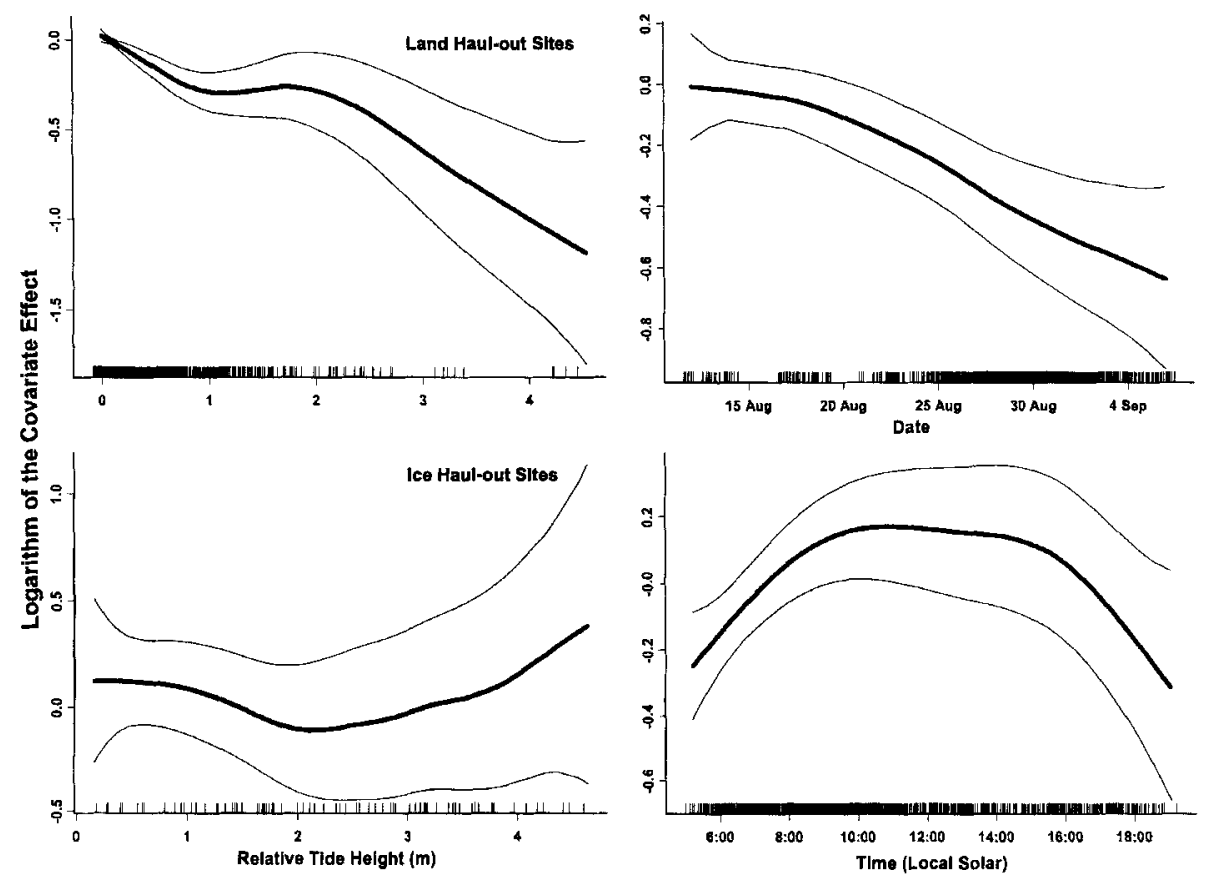

Figure 2. Smooth term components of the additive model for aerial survey counts of Alaska harbor seals: relative tide height at land and ice haul-out sites, date, and time. For a particular value of a covariate (on horizontal axis), the effect on the expected number of seals, as a multiplier of the site mean, can be obtained as the natural anti-logarithm of the corresponding value (middle, bold curve) on the vertical axis. Upper and lower curves represent approximate 95\% pointwise confidence intervals. "Rug" plot across bottom of each panel shows covariate values for all observations, "jittered" to reduce overlap of identical values.

of date on the counts was not significantly different from linear, the apparent flatness around late July and early August may indicate that the highest counts would have been obtained if surveys had begun just slightly prior to ours. The effect of time of day (Fig. 2) indicated that the number of seals hauled out tends to be highest from late morning until mid-afternoon (local solar time). The factor covariates had little effect on the numbers of seals counted, except that counts decreased sharply under high winds and rainy skies (Fig. 3).

\section{A Covariate-Adjusted Count and an Estimate of Total Abundance}

Based on the estimated covariate effects, we created an adjusted index of harbor seal counts that would be expected at ideal states of the covariates: a hypothetical count on 12 August (the first date of our surveys and the date with the largest positive effect on the counts), at low tide ( $0 \mathrm{~m}$ relative tide height), at 1058 local solar time, with partly cloudy skies and calm winds. For haul-out sites on ice, no adjustment was made for an effect of relative tide height. The sum of this adjusted index (or adjusted count) over all sites was 30,035 seals, or 1.84 times the sum of the un- 


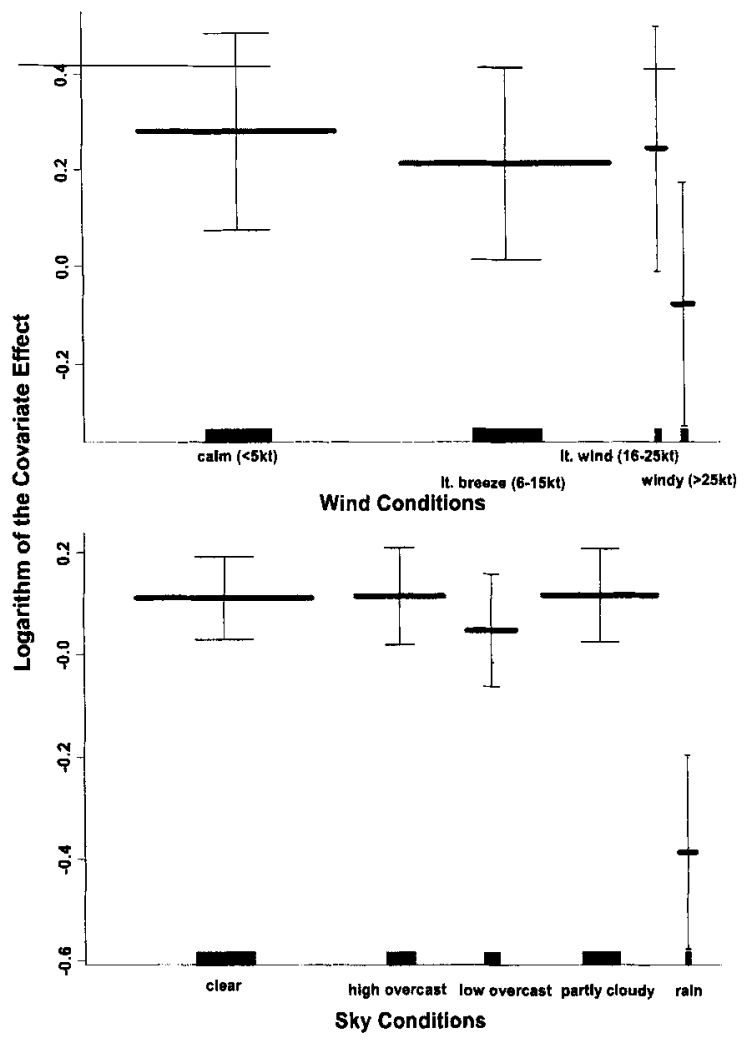

Figure 3. Factor components of additive model for aerial survey counts of Alaska harbor seals: wind and sky conditions. Means and approximate $95 \%$ confidence intervals shown for each level of each factor. For a particular level of a factor (on horizontal axis), effect on expected number of seals, as multiplier of site mean, can be obtained as natural anti-logarithm of corresponding mean (bold line) on vertical axis. "Rug" plot across bottom of each panel shows covariate values for all observations, "jittered" to reduce overlap of identical values.

adjusted site means. To the adjusted count, we applied the correction factor of $1.198(\mathrm{SE}=0.039)$ obtained by Simpkins et al., ${ }^{2}$ yielding 35,981 seals (SE = 1,833 ) as an estimate of the population size of harbor seals in the Gulf of Alaska in 1996. This estimate was 2.2 times the sum of the unadjusted site means.

\section{DisCussion}

\section{The Effects of Covariates}

The influences of the covariates on the timing and characteristics of harbor seal haul-out behavior were mostly consistent with findings from previous studies. For example, many authors have reported peaks in the number of harbor seals hauled out around low tide (e.g., Schneider and Payne 1983, Allen et al. 1984, Pauli and Terhune 1987a, Frost et al. 1999) such as we observed at terrestrial haul-out sites. Stewart (1984) described diurnal haul-out patterns in the Channel 
Islands, California, where sandy haul-out sites were available to seals irrespective of tides, similar to what we observed on glacial ice haul-outs.

Similarly, the effect that we observed of rain and wind on haul-out behavior agrees with other studies in which more seals were observed swimming in the water around haul-out sites when it was raining (Pauli and Terhune 1987b, Olesiuk et al. 1990) or more seals were hauled out when winds were not strong and rain was not heavy. ${ }^{4}$ These effects on haul-out behavior, however, may be difficult to distinguish from effects of these conditions on observers' abilities to detect and count seals.

The effect we observed related to the date covariate was likely a reflection of changes in harbor seal behavior corresponding to the annual molt period. Individuals spend more time hauled out during the molt, possibly to elevate skin temperature and conserve energy (Boily 1995). Once molting is completed, harbor seals haul out less frequently and for shorter periods of time (Sullivan 1980, Thompson et al. 1989, Thompson and Harwood 1990, Frost et al. 2001). For example, Mathews and Kelly (1996) observed that counts of seals in mid-September were $85 \%$ less than counts in the same area made three weeks earlier (late August) in Glacier Bay, Alaska. This postmolt decline may explain the decrease in our estimated numbers of seals ashore from mid-August to early September. However, the timing of the molt varies among the sexes and age classes and the relative timing among age classes may vary from year to year (Thompson and Rothery 1987, Daniel et al. ${ }^{5}$ ). Therefore, the date of the peak number of seals ashore may also vary, confounding attempts to time aerial surveys around the peak date. This possibility reinforces the notion that covariate effects should be taken into account explicitly in estimates of harbor seal abundance from aerial surveys. An important implication for survey design is that some survey effort should be allocated to dates that are expected to be sub-optimal for numbers of seals hauling out, to provide the "contrast" necessary for reliable estimation of the date effect.

Of the two measures of tide height that we investigated, relative tide height was much better than the absolute height of the tide for explaining variation in the seal counts. Making the tidal measure relative to the low tide took into account the day-to-day variations in the range of the tide. The better fit to this variable confirmed that the importance of the tide was not simply an issue of space available for hauling out; it was also a matter of the timing of behavior around the low tide, irrespective of the absolute height of the low tide (Olesiuk 1999). That we found the (relative) tide height to be a slightly better predictor than relative tide time, unlike Frost et al. (1999), actually reflects the similarity of information conveyed by these two variables; prevalence of one over the other is likely to vary among studies due only to slight differences in the data that may not be of biological significance. For example, in a study of haul-out behavior at two sites in Alaska, Simpkins et al. ${ }^{2}$ found that relative tide height was

\footnotetext{
${ }^{4}$ Withrow, D. E., and T. R. Loughlin. 1996. Abundance and distribution of harbor seals (Phoca vitulina richardsi) along the north side of the Alaska Peninsula and Bristol Bay during 1995. Annual report (unpublished). Office of Protected Resources, National Marine Fisheries Service, 1335 EastWest Highway, Silver Spring, MD 20910.

${ }^{5}$ Daniel, R., L. A. Jemison, G. W. Pendleton and S. M. Crowley. Molting phenology of harbor seals on Tugidak Island, Alaska. Alaska Department of Fish and Game, Division of Wildlife Conservation, P. O. Box 240020, Douglas, Alaska 99824, U.S.A.
} 
the best predictor of the proportion of seals hauled out at one site and relative tide time was the best predictor at the other site.

\section{Glacial Ice Haul-out Sites}

Our results indicated that harbor seal haul-out behavior in glacial ice habitats was not strongly influenced by tidal stage, consistent with other studies (Calambokidis et al. 1987, authors' unpublished data). Presumably, that is because the accessibility of a haul-out site that always floats at the water surface is not dependent on tide level. Although in one respect this simplifies the design and execution of surveys for harbor seals using glacial ice haul-outs, these sites remain difficult to survey reliably for other reasons. The primary problems are that occasionally the ice is dirty and that the floating ice fields emanating from glaciers tend to be widely dispersed and constantly in motion; therefore, it is difficult for aerial observers to distinguish seals from dirt and rocks and to keep track of what areas have been counted or photographed. Until a more reliable method of surveying these sites is available, there will be uncertainty associated with counts from areas such as Columbia Bay, Icy Bay, Harriman Fjord, and College Fjord in Prince William Sound, where several hundred to more than a thousand seals may be hauled out during the molt.

\section{Comparison of Two Different Treatments of Prince William Sound Data}

The analyses presented here included data that were used by Frost et al. (1999) in their study of trends in harbor seal numbers in Prince William Sound. For the 17 haul-out sites in common between the two data sets (Fig. 1, Zone 6, Route A), we computed an unadjusted mean count of 718 seals and an index adjusted for the covariates of 981 seals (Table 2). Frost et al. (1999) reported an unadjusted mean count of 808 seals and an adjusted index of 966 seals for 1996. The unadjusted means were different because we included more replicate observations at some of the sites than Frost et al. (1999). They eliminated one survey day from their data because that day was rainy, the survey did not cover all of their 25 sites, and the low counts obtained on that day would have biased their results because they did not include weather conditions as covariates. In our study, however, we included weather conditions among the covariates and thus retained the counts from the rainy day, making our unadjusted mean count lower than that reported by Frost et al. (1999). Also, we included counts from seven of the 25 Route A sites on 12-14 August, just prior to the surveys reported by Frost et al. (1999). Despite the differences in the counts that formed the basis of the two analyses, the covariate-adjusted indices were very similar (981 vs. 966), supporting the notion that covariate adjustment is beneficial for reducing variability in harbor seal counts.

The magnitude of our covariate adjustment for Prince William Sound (1.4 times the unadjusted mean) was greater than that of Frost et al. (1999) (1.2 times the unadjusted mean), possibly because our model included more covariates, and the optimal states of the covariates imply upward adjustments of the means. This result emphasizes the importance of recording as many of the potential covariates as possible during surveys such as these. Important covariates miss- 
ing from a model can cause over-dispersion and under-adjustment for the covariate effects.

With a few minor exceptions, the covariate effects described in other analyses of counts from Prince William Sound (Frost et al. 1999; Ver Hoef and Frost, in press) were supported in our analysis of counts from the broader Gulf of Alaska region. We found a similar relationship of counts declining with date from midAugust into September. Seals in Prince William Sound, however, tended to haul out in greatest numbers in the early morning (Ver Hoef and Frost, in press), rather than around midday, which was the case on average for the Gulf of Alaska as a whole. We found a more significant effect from (relative) tide beight than found by Frost et al. (1999) for the Prince William Sound sites, but they found the time relative to the tide to be more important so that the overall effect of the tide was similar in both studies. As we suggested above, these differences in response to tidal variables are unlikely to be of biological significance.

\section{Estimating Total Population Size}

Our approach to estimating the population size of harbor seals accounted for both the effect of covariates on survey counts and the proportion of seals that remained in the water under ideal haul-out conditions. Previous estimates of harbor seal population sizes used the average proportion of marked animals hauled out during replicate survey flights to correct survey counts for the proportion of the total population that was at sea (and therefore not counted) during the survey (e.g., Huber et al. 2001). The effect of environmental conditions on haul-out behavior and survey counts was implicitly included in the behavior of the marked animals, which was assumed to represent accurately the haul-out behavior of all surveyed animals. This approach was adequate for small-scale surveys in which all haul-out sites could be surveyed under similar environmental conditions. During large-scale surveys, however, not every haul-out site can be surveyed under the same conditions, and the behavior of marked animals at one site may not represent the behavior of animals at another site experiencing different environmental conditions.

Recent studies created statistical models of the relationship between survey counts and environmental conditions at each haul-out site to explicitly adjust counts for the effects of environmental covariates (Watts 1996, Frost et al. 1999). This approach was adequate for use in analyses of population trends because counts at all sites could be adjusted to a standard set of environmental conditions, and trends in those adjusted counts could be assumed to represent population trends (Frost et al. 1999).

We extended this approach to obtain an actual population size estimate by applying to our adjusted counts a covariate-adjusted correction factor to account for the proportion of seals not hauled out (i.e, at sea) under the standard conditions. In a study of radio-tagged harbor seals during the molt season, Simpkins et $a l^{2}$ derived such a covariate-adjusted correction factor, and they found that the proportion of seals at sea was very similar for two widely-separated sites in Alaska under conditions that were ideal for each site. Based on this similarity in values between sites, Simpkins $e t a l^{2}$ suggested that harbor seals in different regions behave similarly under locally ideal conditions, at least within Alaska during the molt season. We assumed that was true and applied the correction factor 
from Simpkins $e t a l^{2}$ to our adjusted counts to estimate the population size of harbor seals in the Gulf of Alaska. This assumption, however, should be explored further by obtaining estimates of the haul-out proportions and ideal conditions at additional sites and by direct comparison of covariate adjustment models for data obtained simultaneously by surveys and monitoring of radio-tagged harbor seals.

\section{ACKNOWLEDGMENTS}

We are grateful to T. R. Loughlin for program management and to the following persons for their assistance in flying the aerial surveys: M. Beeson, L. F. Lowry, B. Mahoney, P. Olesiuk, M. Payne, and K. Wynne. We also thank J. K. Jansen for help in matching tidal stations to seal haul-out sites. S. Buckland, R. Fewster, and A. York provided helpful comments on analyses. G. VanBlaricom, J. Sterling, and an anonymous reviewer provided suggestions that improved the manuscript. This project received financial support from the National Marine Fisheries Service/NOAA, the Alaska Department of Fish and Game, the National Research Council (to M. A. Simpkins), the Exxon Valdez Oil Spill Trustee Council (to K. J. Frost), and the Exxon Corporation (to J. J. Burns).

\section{Literature Cited}

Allen, S. G., D. G. Ainley, G. W. Page and C. A. Ribic. 1984. The effect of disturbance on harbor seal haul out patterns at Bolinas Lagoon, California. Fishery Bulletin, U.S. 82:493-500.

BoILY, P. 1995. Theoretical heat flux in water and habitat selection of phocid seals and beluga whales during the annual molt. Journal of Theoretical Biology 172:235-244.

Calambokidis, J., B. L. Taylor, S. D. Carter, G. H. Steiger, P. K. Dawson and L. D. ANTRIM. 1987. Distribution and haul out behavior of harbor seals in Glacier Bay, Alaska. Canadian Journal of Zoology 65:1391-1396.

Fewster, R. M., S. T. Buckland, G. M. Siriwardena, S. R. Baillie and J. D. Wilson. 2000. Analysis of population trends for farmland birds using generalized additive models. Ecology 81:1970-1984.

Frost, K. J., L. F. Lowry AND J. J. Burns. 1982. Distribution of marine mammals in the coastal zone of the Bering Sea during summer and autumn. U.S. Department of Commerce, National Oceanic and Atmospheric Administration Outer Continental Shelf Environmental Assessment Program Final Report 20(1983):365-561.

Frost, K. J., L. F. Lowry and J. M. Ver HoEr. 1999. Monitoring the trend of harbor seals in Prince William Sound, Alaska, after the Exxon Valdez oil spill. Marine Mammal Science 15:494-506.

Frost, K. J., M. A. Simpkins AND L. F. Lowry. 2001. Diving behavior of subadult and adult harbor seals in Prince William Sound, Alaska. Marine Mammal Science $17: 813-834$.

Goodman, L. A. 1960. On the exact variance of products. Journal of the American Statistical Association 55:708-713.

Hanan, D. A. 1996. Dynamics of abundance and distribution for Pacific harbor seal, Phoca vitulina richardsi, on the coast of California. Ph.D. dissertation, University of California, Los Angeles, CA. 158 pp.

Harvey, J. T. 1987. Population dynamics, annual food consumption, movements, and dive behaviors of harbor seals, Phoca vitulina, in Oregon. $\mathrm{Ph} . \mathrm{D}$. dissertation, Oregon State University, Corvallis, OR. 177 pp.

Hastie, T. J., and R. J. Tibshirani. 1990. Generalized additive models. Chapman and Hall, New York, NY. 
HICKs, S. D. 1989. Tide and current glossary. U.S. Dept. of Commerce, National Oceanic and Atmospheric Administration, National Ocean Service. Rockville, MD. $30 \mathrm{pp}$.

Hoover-Miller, A., K. R. Parker and J. J. Burns. 2001. A reassessment of the impact of the Exxon Valdez oil spill on harbor seals (Phoca vitulina richardsi) in Prince William Sound. Marine Mammal Science 17:111-135.

Huber, H. R., S. J. Jeffries, R. F. Brown, R. L. Delong and G. VanBlaricom. 2001. Correcting aerial survey counts of harbor seals (Phoca vitulina richardsi) in Washington and Oregon. Marine Mammal Science 17:276-293.

Jemison, L. A., AND B. P. Kelly. 2001. Pupping phenology and demography of harbor seals (Phoca vitulina richardsi) on Tugidak Island, Alaska. Marine Mammal Science 17:585-600.

Lawless, J. F. 1987. Negative binomial and mixed Poisson regression. Canadian Journal of Statistics 15:209-225.

loughijn, T. R., A. S. Periov and V. A. Vladimirov. 1992. Range-wide survey and estimation of total number of Steller sea lions in 1989. Marine Mammal Science $8: 220-239$.

Lowry, L. F., K. J. Frost, J. M. Ver Hoef and R. A. Delong. 2001. Movements of satellite-tagged subadult and adult harbor seals in Prince William Sound, Alaska. Marine Mammal Science 17:835-861.

Mathews, E. A., AND B. P. Kelly. 1996. Extreme temporal variation in harbor seal (Phoca vitulina richardsi) numbers in Glacier Bay, a glacial fjord in southeast Alaska. Marine Mammal Science 12:483-489.

McCullagh, P., AND J. A. Nelder. 1989. Generalized linear models. Chapman and Hall/ CRC, Boca Raton, FL.

Olesiuk, P. F. 1999. An assessment of the status of harbour seals (Phoca vitulina) in British Columbia. Canadian Stock Assessment Secretariat Research Document 99/33. Fisheries and Oceans Canada, Ottawa, Ontario, Canada. 130 pp.

Olesiuk, P. F., M. A. Bigg and G. M. Eliss. 1990. Recent trends in the abundance of harbour seals, Phoca vitulina, in British Columbia. Canadian Journal of Fisheries and Aquatic Sciences 47:992-1003.

Pauli, B. D., AND J. M. Terhune. 1987a. Tidal and temporal interaction on harbour seal haul-out patterns. Aquatic Mammals 13:93-95.

Pauli, B. D., ANd J. M. Terhune. 1987b. Meteorological influences on harbour seal haulout. Aquatic Mammals 13:114-118.

Pitcher, K. W. 1990. Major decline in number of harbor seals, Pboca vitulina ricbardsi, on Tugidak Island, Gulf of Alaska. Marine Mammal Science 6:121-134.

Pitcher, K. W., and D. G. Calkins. 1979. Biology of the harbor seal (Phoca vitulina richardsi) in the Gulf of Alaska. U.S. Department of Commerce, National Oceanic and Atmospheric Administration, Outer Continental Shelf Environmental Assessment Program Final Report 19(1983):231-310.

Pitcher, K. W., AND D. C. MCAllister. 1981. Movements and haulout behavior of radio-tagged harbor seals, Phoca vitulina. Canadian Field-Naturalist 95:292-297.

SChNeider, D. C., AND P. M. PAYNe. 1983. Factors affecting haulout of harbor seals at a site in southeastern Massachusetts. Journal of Mammalogy 64:518-520.

StewarT, B. S. 1984. Diurnal hauling patterns of harbor seals at San Miguel Island, California. Journal of Wildlife Management 48:1459-1461.

Stewart, B. S., S. Leatherwood, P. K. Yochem and M. P. Heide-Jørgensen. 1989. Harbor seal tracking and telemetry by satellite. Marine Mammal Science 5:361-375.

Sullivan, R. M. 1980. Seasonal occurrence and haulout use in pinnipeds along Humboldt County, California. Journal of Mammalogy 61:754-759.

ThOMPSON, P. M., AND J. HaRWOOD. 1990. Methods for estimating the population size of common seals (Pboca vitulina). Journal of Applied Ecology 27:924-938.

ThOMPSON, P., AND P. ROTHERY. 1987. Age and sex differences in the timing of moult in the common seal, Phoca vitulina. Journal of Zoology, London 212:597-603. 
Thompson, P. M., M. A. Fedak, B. J. McConnell and K. S. Nichol.as. 1989. Seasonal and sex-related variation in the activity patterns of common seals (Phoca vitulina). Journal of Applied Ecology 26:521-535.

Thompson, P. M., D. Miller, R. Cooper And P. S. Hammond. 1994. Changes in the distribution and activity of female harbour seals during the breeding season: Implications for their lactation strategy and mating patterns. Journal of Animal Ecology $63: 24-30$.

Venables, W. N., and B. D. Ripley. 1999. Modern applied statistics with S-PLUS. Springer-Verlag, New York, NY.

Ver HoEf, J. M., AND K. J. Frost. In press. Bayesian hierarchical models for estimating harbor seal changes in Prince William Sound, Alaska. Environmental and Ecological Statistics.

WATTS, P. 1996. The diel hauling-out cycle of harbour seals in an open marine environment: Correlates and constraints. Journal of Zoology, London 240:175-200.

Yochem, P. K., B. S. Stewart, R. L. DeLong and D. P. DeMaster. 1987. Diel hauling patterns and site fidelity of harbor seals (Pboca vitulina richardsi) on San Miguel Island, California, in autumn. Marine Mammal Science 3:323-332.

Received: 12 July 2001 Accepted: 6 June 2002 